\title{
A Perspectiva Transdisciplinar da Psicanálise
}

\author{
Denise Maria Barreto Coutinho ${ }^{1, *}$ (D), \& Camila Santos Lima Fonteles ${ }^{1}$ (D) \\ ${ }^{1}$ Universidade Federal da Bahia, Salvador, BA, Brasil
}

\begin{abstract}
RESUMO - Se a interdisciplinaridade foi condição necessária para a construção do campo psicanalítico, a transdisciplinaridade fornece elementos que justificam a pertinência da psicanálise como meio de produção de conhecimento na universidade. Ao estabelecer pontes com diferentes campos, fazendo aquele edifício teórico ser atravessado por marcas outras e modificar-se, Freud transmitiu uma verdadeira experiência, instituindo uma nova episteme. O artigo introduz o contexto de elaboração da obra freudiana e apresenta a hipótese de que há uma antecipação da interdisciplinaridade em Freud. Em seguida, apresenta os termos interdisciplinaridade e transdisciplinaridade. Por fim, defende a tese de que o estatuto da psicanálise corresponde mais à práxis transdisciplinar do que ao simples diálogo ou integração interdisciplinar.
\end{abstract} PALAVRAS-CHAVE: transdisciplinaridade, interdisciplinaridade, psicanálise, ciência contemporânea, complexidade

\section{The Transdisciplinary Perspective of Psychoanalysis}

\begin{abstract}
If interdisciplinarity was a necessary condition for the construction of the psychoanalytical field, transdisciplinarity provide evidence to justify the relevance of psychoanalysis as a mean of knowledge production at the university. By building bridges across different fields, while making other brands cross that theoretical edifice and be modified, Freud transmitted a true experience, instituting a new episteme. This article introduces the context of development of Freud's work and presents the hypothesis that there is an anticipation of interdisciplinarity in Freud. Then, it discusses the terms interdisciplinarity and transdisciplinarity. Finally, it argues that the status of psychoanalysis corresponds more to transdisciplinary practice than the simple dialogue or interdisciplinary integration.
\end{abstract}

KEYWORDS: transdisciplinary, interdisciplinary, psychoanalysis, contemporary science, complexity

Desde o início de sua carreira como cientista, Freud (1895/1996) empreendeu esforços para que a psicanálise fosse compreendida como ciência de pleno direito, situando-a no âmbito das ciências da natureza. Contudo, também defendia que a psicanálise não constitui uma ciência como as outras. Como veremos adiante, Freud advoga um lugar intermediário entre as ciências da natureza e as ciências humanas, usando a metáfora da ponte e a figura de "entrelugar" para indicar tal proposição. Ao tempo em que traz para a cena científica conceitos como inconsciente, pulsão, transferência, "destaca o que a ciência despreza, o insignificante, os sonhos, os chistes, os lapsos, os detalhes ditos secundários do discurso, equívocos, enigmas, $\mathrm{o}$ nonsense, o grotesco, o cômico, as brincadeiras infantis" (Coutinho, 2004, p.15). Tal movimento desestabiliza o universo das ciências tradicionais, sobretudo numa época fortemente marcada pelo positivismo.
Essa constituição plural da psicanálise contribuiu fortemente para aproximá-la do ambiente universitário, lócus de produção do conhecimento, da pesquisa e da formação nas mais diversas áreas. Sendo a psicanálise teoria, práxis e investigação, seria natural que os caminhos se cruzassem. No entanto, tais relações nunca foram fáceis e livres de tensões. Contemporaneamente, a psicanálise vem adentrando cada vez mais claramente na universidade, sendo esta um potente meio produtor e divulgador das ideias psicanalíticas e um lugar no qual a psicanálise se defronta e dialoga com outros campos de saberes e práticas, alimentando e sendo alimentada por confrontos, impasses, desafios e projetos que compõem o universo acadêmico formal.

Freud convoca saberes de diversas naturezas e alcança outros campos ao estabelecer relações com física, química, biologia, medicina, artes, educação, linguística, antropologia etc. Tal movimento, longe de configurar um

\footnotetext{
*E-mail: denisecoutinho1@gmail.com

- Submetido: 01/07/2016; Revisado: 25/09/2018; Aceito: 01/10/2018.
} 
simples diletantismo erudito de Freud, indica, ao invés, sua disposição interdisciplinar, avant la lettre. Ele soube reunir as contribuições mais recentes das ciências do século XIX, sem negligenciar o solo filosófico e artístico da antiguidade grega, bem como contribuições de seu tempo. Nesses saberes, ele encontra uma espécie de confirmação de suas descobertas.

O objetivo deste trabalho não é discorrer sobre interações da psicanálise com outros saberes, mas antes indicar a originalidade de Freud ao buscar interseções, diálogos e relações com outros campos, num claro esforço para o que hoje chamaríamos de transdisciplinar, em uma época marcada pela fragmentação e pelo cientificismo, com alto grau de hierarquização entre saberes. Não é apenas a demonstrada constituição interdisciplinar da psicanálise por Freud ou sua práxis transdisciplinar o que nos chama a atenção, mas seu esforço de promovê-la nessas bases, na universidade, isto é, como ensino, pesquisa e transmissão, constituindo um dentro-fora transdisciplinar para a formação de analistas.

\section{CONFORMAÇÃO INTERDISCIPLINAR}

A psicanálise não se reduz a uma forma de tratamento, não é um sistema filosófico, uma medicina psiquiátrica ou uma psicologia. Inúmeros são os momentos em que Freud busca desvencilhar-se da psicologia e da medicina para constituir um campo próprio, ao tempo em que atribui potencialidades de aplicação da psicanálise para outras ciências, para a educação e a cultura. $\mathrm{O}$ termo psicanálise aplicada por muito tempo foi visto de forma pejorativa por psicanalistas (e mesmo hoje), pois pode resvalar para um uso selvagem ou para uma acepção de adaptação ou panaceia. $\mathrm{O}$ primeiro sentido de uma psicanálise dita aplicada referiu-se à sua divulgação e visava ultrapassar as fronteiras do meio médico:

(...) com a Interpretação dos Sonhos a psicanálise ultrapassou os limites de um assunto puramente médico (...) diversas aplicações em áreas da literatura e da estética, em história da religião e pré-história, em mitologia, folclore, pedagogia etc. (...). A maioria dessas aplicações teve seu ponto de partida em meus trabalhos. Aqui e ali eu também prossegui um tanto pelo caminho, para satisfazer tal interesse não médico. Outros, não apenas médicos, mas também especialistas, seguiram minhas pegadas e adentraram os respectivos territórios. (Freud (1925/2011, pp.151-152)

De acordo com nossa proposta, temos aí não mera aplicação, mas integração de objetos e, nessa constituição plural, Freud opera, por um lado, trazendo contribuições do teatro, das artes plásticas, da antropologia para a compreensão de mitos, da religião, das artes como elementos do viver humano. Em outra vertente, porém sem oposição, suas pesquisas em fisiologia e neurologia desempenharam importante e decisivo papel na formulação das bases teóricoclínicas da psicanálise. Em um de seus primeiros textos, Estudos sobre a histeria (Breuer \& Freud, 1895/1996), vemos a explicação para o fato de que seu pensamento e sua escrita assemelham-se bem mais a uma narrativa literária do que a um texto científico. Ele esclarece que não se trata de uma escolha estilística. A "natureza do objeto" impõe tal modo de relato e interpretação.

Freud não parece ter tido qualquer dúvida, ao longo de sua extensa e produtiva vida, quanto a filiar-se ao universo científico, mas é nas artes, na mitologia, na literatura que ele encontra um contraponto à psiquiatria para fundar um novo campo, como ele mesmo diz em Psicanálise e Teoria da libido (1923/2011):

Uma apreciação da psicanálise seria incompleta se deixasse de informar que - única entre as disciplinas médicas - ela mantém amplas relações com as ciências humanas e está prestes a adquirir, para a história da religião e da civilização, a mitologia e a ciência da literatura, uma significação análoga à que tem para a psiquiatria. Isso pode surpreender, quando se considera que originalmente ela não tinha outro objetivo senão compreender e influenciar os sintomas neuróticos. Mas é fácil indicar onde se estabeleceu a ponte para as ciências humanas. Quando a análise dos sonhos levou a uma percepção dos processos psíquicos inconscientes e mostrou que os mecanismos que geram os sintomas patológicos também agem na vida psíquica normal, a psicanálise se tornou psicologia da profundeza e, como tal, capaz de ser aplicada às ciências humanas; pôde resolver uma série de questões ante as quais a psicologia oficial da consciência detinha-se perplexa. (pp.299300 , grifo do autor)

Este trecho explicita claramente a ruptura. Nem a tradicional psicologia da consciência nem a recente psiquiatria haviam conseguido fornecer respostas e promover diálogo com as humanidades. Tal percepção foi possível porque Freud teve sólida formação filosófica. Seguiu o curso de Franz Brentano na Universidade de Viena, era leitor de Platão, Aristóteles, Kant, Schopenhauer e Nietzsche. Ele reconhece a antecipação de sua teoria do recalque em Nietzsche e em Schopenhauer (Assoun, 1978). No entanto, manteve uma postura conscientemente distanciada da filosofia. Em As resistências à psicanálise (1925/2011), afirmou: “o psíquico dos filósofos não era o da psicanálise” (p.257). Seus esforços vão sempre na direção de incluir a psicanálise no campo das ciências e a filosofia se distancia do ideal científico ao pretender uma imagem de mundo coerente, dominada pela consciência. Nesse mesmo texto, Freud localiza a psicanálise num entre-lugar problemático: "a psicanálise tira apenas desvantagens de sua posição intermediária entre medicina e filosofia" (p.259). Se a medicina toma a psicanálise como um sistema 
especulativo, diz Freud, a filosofia a acusa de "premissas impossíveis" e falta de precisão.

Em relação às artes, desde cedo em sua obra, Freud preconiza que as mesmas forças motrizes que constituem um artista estão igualmente presentes nas pessoas sadias e em neuróticos. Seu ensaio sobre Leonardo da Vinci (1910) e, antes dele, Romances familiares (1909/1996) demonstram como ele considera as histórias familiares "como obras de ficção" (p. 221). Não podemos esquecer ainda a análise sobre a escultura Moisés, de Michelangelo.

Já em relação à literatura, talvez se possa conjecturar que Freud comungaria da posição expressa por Barthes (1997): "Se, por não sei que excesso do socialismo ou da barbárie, todas as nossas disciplinas devessem ser expulsas do ensino, exceto numa, é a disciplina literária que devia ser salva, pois todas as ciências estão presentes no monumento literário" (p.18). Coutinho (2004) afirma que a literatura "se impôs a Freud, não para ilustrar sua clínica, mas para confirmar o caráter material da linguagem na produção de sujeitos humanos, sendo para a fundação da psicanálise o Outro discurso, externo/interno, que lhe forneceu consistência de campo do saber" (p.69). Freud via na literatura uma antecipação das questões psíquicas trabalhadas posteriormente pela psicanálise:

Os escritores criativos são aliados muito valiosos, cujo testemunho deve ser levado em alta conta, pois costumam conhecer toda uma vasta gama de coisas entre o céu e a terra com as quais a nossa filosofia ainda não nos deixou sonhar. Estão bem adiante de nós, gente comum, no conhecimento da mente, já que se nutrem em fontes que ainda não tornamos acessíveis à ciência. (Freud, 1907/1996, p.20)

Ao longo da obra, permanece a ideia de que as contribuições da literatura estão "entre as mais fascinantes aplicações da psicanálise” (Freud, 1914/2012a, p. 286). Podemos citar algumas aproximações, como a análise do caso Schreber, na qual privilegia a vertente clínica, a análise da Gradiva de Jensen, a obra $O$ estranho, a partir do conto $O$ homem de areia de E.T.A Hoffmann entre outros, como nos mostra Assoun (1997) ao fazer uma lista retrospectiva de autores e obras literárias discutidas por Freud. No texto sobre a análise leiga (1926/1996), Freud faz referência a uma ciência da literatura, mencionada junto com a história da civilização, da mitologia e da psicologia da religião, como saberes que concernem à psicanálise. A literatura, portanto, sempre esteve em lugar privilegiado entre as aplicações da psicanálise.

Destaca-se também o interesse de Freud pelo que hoje diríamos ser objeto da sociologia e antropologia, como Totem e tabu (1913), Psicologia das massas e análise do Eu (1920), Mal-estar na civilização (1930), O futuro de uma ilusão (1933) e Moisés e o Monoteísmo (1937), textos nos quais as relações com a cultura, a constituição da família, do laço social e da sociedade são contempladas.
Os primeiros membros da Sociedade Psicanalítica de Viena tinham formações diversas. Vários deles, nãomédicos, empenharam-se para encontrar em suas atividades um equivalente da prática clínica ao mesmo tempo em que analistas médicos estabeleciam relações entre psicanálise e saberes diversos, como nos relata Freud (1923/2011):

C. G. Jung foi o primeiro a enfatizar a espantosa coincidência entre as desordenadas fantasias dos doentes de dementia praecox e os mitos de povos primitivos; o presente autor chamou a atenção para o fato de que os dois desejos que formam o complexo de Édipo têm conteúdo igual ao das duas proibições capitais do totemismo (não matar o ancestral e não desposar uma mulher do próprio clã), e disso tirou conclusões de vasto alcance. (...). Otto Rank lançou viva luz sobre a mitologia e a história da literatura, aplicando conhecimentos psicanalíticos; Theodor Reik fez o mesmo com a história dos costumes e das religiões, e o pastor Oskar Pfister (de Zurique) despertou o interesse de educadores religiosos e professores, mostrando o valor dos pontos de vista psicanalíticos para a pedagogia. Não cabem, aqui, maiores detalhes sobre essas aplicações da psicanálise; basta observar que ainda não se pode ver até onde irão. (pp.300-301)

Para além da clínica, seus interesses e análises contribuíram para a expansão da psicanálise e estão na origem das institucionalizações com a criação da IPA em 1910. Em 1912, a fundação da Revista Imago por Hans Sachs e Otto Rank propicia relações dialógicas da psicanálise com as ciências humanas. A formalização do ensino psicanalítico foi estratégica, pois, sendo um campo novo, Freud antevia o risco de a psicanálise tornar-se uma psicologia geral e ter a clínica como aplicação técnica. Apesar do dogmatismo presente nas instituições, um dos objetivos da IPA era "Cultivar e promover a ciência psicanalítica fundada por Freud, tanto como pura psicologia como em sua aplicação à medicina e às ciências humanas" (Freud, 1914/2012a, p. 296). Hans Sachs, um dos primeiros analistas didatas e figura importante na história da formação analítica, não era médico e ministrava cursos no Instituto de Berlim (primeira instituição formadora criada em 1920) sobre aplicações da psicanálise às ciências humanas.

Logo seguiu-se a publicação, em 1913, do livro Psicanálise e Ciências Humanas de Otto Rank e Hans Sachs. Os autores tratam da importância da psicanálise para as ciências humanas e as relações estabelecidas em parte pela aplicação da teoria do inconsciente e, por outro lado, por ser uma jovem ciência, sob a dependência de influências externas e contingentes (Rank \& Sachs, 1913/1980). Os autores dedicam um capítulo ao inconsciente e suas formas de expressão e explicitam contribuições da psicanálise para o estudo de mitos e contos, em interface com a ciência das religiões, a etnologia e a linguística, a estética e a psicologia da arte, a filosofia, a ética e o direito, a pedagogia, enfim, os mesmos campos descritos por Freud em $O$ interesse $d a$ psicanálise, publicado no mesmo ano. 
Nessa obra (1913/2012), vemos o Freud interdisciplinar avant la lettre que considera as positivas e "inesperadas relações" que a "jovem ciência" pode aportar "para outros profissionais além dos psiquiatras" (p.330). Seu argumento principal é que há "grande número de fenômenos ligados à expressão corporal e à linguagem, e também processos de pensamento - tanto em pessoas normais como doentes -, que até agora não foram objeto da psicologia" (p.330). Além disso, advoga uma linha de abordagem psicológica, advinda das descobertas psicanalíticas, que nem mesmo cem anos depois parecem ter sido suficientemente exploradas: o estudo de fenômenos por ele descritos nos quais "tanto os processos normais como os patológicos obedecem às mesmas regras" (p.331); atos falhos e sonhos são amplamente explorados e "constituem a mais relevante contribuição da psicanálise à psicologia" (p.335). Ainda nesse texto, Freud aborda "O interesse da psicanálise para as ciências não psicológicas", no qual destacará as seguintes disciplinas acadêmicas: ciência da linguagem, filosofia, biologia, história da evolução, história da civilização, estética (em que trata das artes), sociologia e pedagogia.

As relações entre psicanálise e psiquiatria continuam sendo exploradas nas Conferências Introdutórias a Psicanálise (1917/2014), particularmente num trecho intitulado "Psicanálise e Psiquiatria" em que ele não opõe as duas ciências, mas as coloca em posição de complementaridade:

(...) não há, na essência do trabalho psiquiátrico, nada que poderia se opor à pesquisa psicanalítica. Logo, são os psiquiatras que se opõem à psicanálise, e não a psiquiatria. A psicanálise está para a psiquiatria assim como a histologia para a anatomia; uma estuda a forma exterior dos órgãos, ao passo que a outra se dedica ao estudo de sua constituição a partir dos tecidos e células. Não se pode conceber uma contradição entre estudos que dão continuidade um ao outro. (p. 341)

No que diz respeito à inserção da psicanálise na universidade alemã, destacamos dois exemplos em Deve-se ensinar a psicanálise nas universidades? (1919/2010). Ele defende a inserção da psicanálise na formação não apenas médica, mas de outras áreas, visando suprir lacunas no ensino em relação a fatores psíquicos nas enfermidades e seu tratamento. Em seguida, na psiquiatria que, na época, era meramente descritiva. Ele propõe ali a psicanálise como propedêutica para literatura, artes, história, filosofia, religião. Freud defende a psicanálise na universidade, enfatizando, porém, que a universidade não forma o psicanalista. É incontestável para ele que o ensino da psicanálise traz benefícios para a universidade. Como a história demonstra, a psicanálise precisou, sim, bastante da universidade, inicialmente como meio de divulgação e, posteriormente, como lugar de produção de conhecimento e aporte de referências. Mesmo se um analista não se forma nos bancos universitários, é impossível negar contribuições da psicanálise no desenvolvimento da universidade e na formação do analista.

No texto A questão da análise leiga (1926/1996), Freud diz que, se houvesse uma "faculdade de psicanálise" (p.236), seriam necessárias muitas matérias na Faculdade de Medicina, especificamente psiquiatria, biologia, psicologia das religiões e literatura. $\mathrm{O}$ texto é rico em abordar relações com outros saberes. Freud comenta que colegas, doutores em filosofia ou pedagogos, assim como pessoas leigas, submetidas à análise e à formação completa podem tornarse psicanalistas mais competentes do que médicos que não fazem tal formação. No Apêndice, escrito em 1927, Freud acrescenta à paleta de conhecimentos necessários à formação analítica os seguintes campos: "elementos das ciências mentais, da psicologia, da história e do estudo da evolução" (p.242). Em relação a uma suposta predominância do ensino médico, ele adverte: "analistas médicos não formados eram ainda mais perigosos que os leigos" (p. 246).

O programa de estudos do Instituto de Berlim, descrito no relatório redigido em comemoração aos dez anos da instituição, considerava necessária aquela ampla formação descrita por Freud. Encontramos cursos de História da Civilização, Psicologia dos Povos, Sociologia e Teoria das Ciências para aprofundar o conhecimento em ciências humanas dos candidatos médicos. Em contrapartida, candidatos não-médicos cursavam biologia, psicologia, sexologia, patologia e psiquiatria. A maioria dos que procuravam o Instituto eram médicos, mas havia também religiosos e pessoas de diferentes profissões como Serviço Social, Letras, Enfermagem, Pedagogia, Engenharia. Encontravam-se cursos com os seguintes temas: "A aplicação da psicanálise nas ciências humanas"; "O lugar da psicanálise nas ciências e na cultura"; "Aplicação da psicanálise nas obras literárias e artísticas" e "O simbólico e sua utilização artística" (Müller-Braunschweig,1985, pp. $79-80)$.

\section{DA INTERDISCIPLINARIDADE À TRANSDISCIPLINARIDADE}

O cenário contemporâneo das ciências produz objetos, métodos e arranjos em interface que levam a novas formas de organização, ultrapassando o âmbito de disciplinas estanques e abrindo caminho a perspectivas inter e transdisciplinares. De acordo com Nicolescu (1999), um dos paradoxos da contemporaneidade é a proliferação acelerada das disciplinas científicas e a consciência cada vez mais maior da ilusão da unidade do conhecimento.

Os conceitos de multi, inter e transdisciplinaridade caíram no uso comum, sendo utilizados de maneira indiscriminada, muitas vezes, sem rigor. Existe de fato uma dificuldade conceitual, sobretudo em relação ao mais comum 
deles, a interdisciplinaridade, amplamente utilizado nos mais diversos contextos (Pombo, 2008).

De acordo com Jantsch (1972 citado por Almeida-Filho, 2005), multidisciplinaridade compreende a justaposição de disciplinas, sem cooperação entre elas. Quanto à interdisciplinaridade, existiria uma problemática comum a diferentes disciplinas que se relacionam. Mais que uma junção, haveria recombinação de elementos. Piaget (1972) pensa a interdisciplinaridade como integração recíproca entre disciplinas, produzindo enriquecimento mútuo. E postula que, longe de ser luxo ou moda, a interdisciplinaridade é "a própria condição do progresso das pesquisas" (1972, p.156). Como exemplo de interdisciplinaridade, Piaget diz que "as matemáticas se constituem como extensão progressiva da lógica" (p. 158), sendo que esta faz parte daquelas como um caso particular das álgebras gerais. É essa assimilação recíproca que, para ele, determina a configuração interdisciplinar. Nicolescu entende interdisciplinaridade como "transferência de métodos de uma disciplina a outra" (2013, p.24). Para ele, tanto na multi quanto na inter, os objetivos se encontram dentro do âmbito disciplinar (2013).

Schmid, Mambrini-Doudet e Hatchuel (2011) propõem outra lógica para compreender a interdisciplinaridade. Partem do pressuposto de que o fracasso de muitos projetos interdisciplinares está na ideia de que é possível criar linguagens comuns entre disciplinas. No entanto, em algumas situações não basta combinar métodos e saberes disciplinares, sendo necessário pensar numa interdisciplinaridade que se alimente, também, da falta de continuidade disciplinar. Mesmo a construção interdisciplinar, lembramos, é submetida a um controle disciplinar.

A lógica interdisciplinar pressupõe outra epistemologia em relação às disciplinas, que inclui multiplicidades históricas e até disciplinares, sem depender destas. Os autores dizem que as redes disciplinares não são suficientes e, diante disto, propõem comunidades científicas em arquipélagos, ou seja, um "lugar da interdisciplina" (p.114). Distinguem interdisciplinaridade, que seria a lógica interdisciplinar a partir de uma epistemologia disciplinar, e interdisciplina, uma lógica tomada sob o ponto de vista da epistemologia genérica. Tal distinção não ocorre completamente no plano empírico. A ideia já não é combinar disciplinas, mas fazer uma imersão ou percolação delas, ou seja, tornar possível modelos contraditórios. Trata-se da construção de um objeto integrativo. O que muda é a noção mesma de objeto e não o fato de passar de uma disciplina a outra. As ciências contemporâneas promovem a construção de objetos integrativos que não podem ser abarcados por uma disciplina, nem tampouco pelo conjunto delas. Esses objetos são construídos por meio de modelagens, por vezes heterogêneas, sendo aceita a incompatibilidade ou a incomensurabilidade entre modelos.

Para Almeida-Filho (2005), os campos disciplinares não podem ser pensados sem levar em consideração os sujeitos que deles participam. Portanto, os campos não constituem estruturas, antes são constituídos por uma práxis científica. Não existem por si só, mas enquanto instituições compostas por sujeitos, agentes que interagem, estando as relações interdisciplinares tendendo mais ao conflito do que ao diálogo. Para que haja comunicação interdisciplinar é necessário produzir discursos que ultrapassem fronteiras e, se isso ocorrer, é porque tais fronteiras não fazem mais sentido. $\mathrm{O}$ autor propõe a transdisciplinaridade como comunicação, não entre campos disciplinares, mas entre agentes em cada campo "pelo trânsito dos sujeitos dos discursos" (p.43). Desta forma, os agentes que circulam nesses campos devem ser capazes de transitar entre as fronteiras, sendo "mutantes metodológicos" (p.44) com uma formação que permita tal movimento qualificado.

Piaget (1972) considera a transdisciplinaridade como etapa superior da interdisciplinaridade, levando essas relações a um patamar sistêmico. Nicolescu (2013) compreende a transdisciplinaridade como uma prática de investigação que se ocupa com o que está entre, através e além das disciplinas, lembrando que seu uso é recente e remonta à década de 1970, com Piaget (Nicolescu, 2013). Nessa acepção, a transdisciplinaridade seria a consequente leitura compreensiva e holística do mundo contemporâneo e implica a presença de vários níveis de realidade (Nicolescu, 2013). Além disso, busca a dinâmica de processos, o que demanda a presença do conhecimento disciplinar. Uma visão transdisciplinar conduz a uma mudança de atitude e perspectiva, sem abdicar, contudo, do conhecimento e da expertise disciplinar.

Diante dos novos fenômenos e objetos que se apresentam na contemporaneidade, os modelos multi e interdisciplinares parecem descritivos e normativos e não dão conta de uma abordagem operativa transformadora. Darbellay (2011) apresenta a transdisciplinaridade como reorganização de saberes disciplinares em vista de um objeto complexo, que não se contenta com partilha de saberes e necessita de um sistema de fronteiras flexíveis entre disciplinas. A ideia de objeto complexo é tributária de uma compreensão nãobinária, não-metafísica, não-linear e emergente, compatível com um sistema de totalidades parciais e mutáveis. Não trabalha com predição nem com determinação causal linear e pode ser parcialmente acessada considerando múltiplos estados de existência e acolhendo o "terceiro excluído".

Nicolescu (2002) aponta três postulados característicos da metodologia transdisciplinar: ontológico (diferentes níveis de realidade), lógico (o terceiro incluído) e epistemológico (estrutura complexa e totalizante). De acordo com Almeida-Filho e Coutinho (2013), há três formas de transdisciplinaridade, levando em consideração objetos/ situações complexas:

TransD 1- Práticas para a formação curricular interdisciplinar (de operadores híbridos ou anfíbios de projetos ou programas de intervenção sobre situações de complexidade). 
TransD 2- Práticas para a pesquisa interdisciplinar (de operadores híbridos ou anfíbios de projetos de projetos de conhecimento de objetos interdisciplinares ou de solução de problemas complexos).

TransD 3- Práticas para a ação interdisciplinar (projetos ou programas de intervenção sobre situações de complexidade). (p. 28)

A inter e a transdisplinaridade seriam estratégias de articulação ou formação do conhecimento, não se configurando como um campo próprio de saber:

considerar campos interdisciplinares estruturados por objetos e métodos de campos disciplinares ou de práticas justifica-se plenamente, de um ponto de vista lógico e epistemometodológico. Mas nada justifica um gueto disciplinar chamado 'a interdisciplinaridade' ou 'a área interdisciplinar', como um espaço residual e delimitado, onde se agrupam e se isolam saberes e práticas que não cabem nos campos disciplinares convencionais. (p. 28)

Escrevendo em 1966 a nota introdutória ao texto Três notas sobre a teoria dos discursos, Althusser redigiu uma circular, nunca publicada, sobre a importância da formação de grupos de trabalhos teóricos. Ele defende, ali, que esses grupos não poderiam constituir-se simplesmente baseados nas disciplinas já existentes, pois sua conformação fragmentada mascara os problemas teóricos nas ciências humanas. Portanto, um grupo de trabalho teórico deveria constituir-se em torno de um problema teórico que pode atravessar diversas disciplinas. Althusser condenava a interdisciplinaridade, pois para ele não se pode construir um objeto interdisciplinar reunindo fragmentos de teorias contraditórias.

A psicanálise, como "ciência do inconsciente" (Freud, 1926/1996, pp.254-255), exige abordagem transdisciplinar, de modo que seus agentes possam estar aptos para o trânsito, como era o desejo de Freud (1913/2012, 1919/2010,
1926/1996). Sua inserção na universidade recoloca a questão da cientificidade pela via do encontro com outros saberes, na medida em que, diante de determinada lógica hegemônica de produção e de pesquisa, via de regra, demonstra-se sua incompatibilidade ética com os supostos da objetividade, da neutralidade e com a exclusão ou, pelo menos, a dificuldade de lidar com ideias como a de sujeito e do vazio da estrutura.

Não há resposta conclusiva para a questão da cientificidade da psicanálise. Algumas críticas incidem sobre tentativas de adaptação, ou, no dizer de Althusser (1966/1993), de anexação a outros domínios. Tampouco haverá unanimidade quanto ao método científico ideal, ao qual todos os campos deveriam submeter-se. Quase quatro séculos se passaram desde que Descartes funda a ciência moderna propondo um método universal e a busca por uma verdade que apreenda totalmente o sujeito. Entretanto, essa busca pelo padrão único e ideal permanece no imaginário social do qual a universidade é tributária. Não é raro encontrar linhas de investigação em psicanálise na universidade que aderem sem questionamento aos parâmetros positivistas. É possível argumentar que as teorias da complexidade acolhem o modelo da psicanálise, na medida em que aceitam (1) múltiplos níveis de realidade, (2) o terceiro incluído e (3) o princípio da contradição (Nicolescu, 2009), mas isto também não é um pensamento unânime. Milner (1996) afirma que o problema da psicanálise seria fazer com que exista um pensamento que não corresponda aos critérios imaginários do pensamento.

A psicanálise deve, portanto, construir uma teoria do pensamento, que integre, não como uma extensão adventícia, mas como uma propriedade constitutiva, o pensamento disjunto das regulações imaginárias [...] Em Lacan, pode-se reconhecer a ambição de uma teoria positiva, que para além do imaginário do pensamento, diz respeito a seu real. (Milner, 1996, p.111, grifo do autor)

\section{CONSIDERAÇÕES FINAIS}

Freud (1925/2011) coloca a psicanálise, como já vimos, em um "entre-lugar". Sua preocupação era não permitir sua submissão à medicina e à psiquiatria. É justamente essa subversão de fronteiras e a integração de saberes, prioritariamente extrauniversitários, o que marca o caráter transdisciplinar da psicanálise. Ao mesmo tempo, consideramos que é necessário avançar na direção da superação da perspectiva transdisciplinar, pois, de acordo com Nicolescu (2013, p.23): "El enfoque transdisciplinario será un complemento indispensable para el enfoque disciplinar".

Diante da encruzilhada posta pela ideia de psicanálise aplicada, pela metáfora da fronteira e também pela noção de risco, Althusser (1964/1996) defende o combate ao que ele chama de anexação da psicanálise, assim como um país anexa outro para minar e subtrair sua força política, instituindo aquele espaço geopolítico como periférico, dependente. Ele interroga o estatuto da psicanálise na sua relação com as ciências humanas, em particular, a psicologia, e apresenta uma série de disciplinas que fazem fronteira com a psicanálise, como a psiquiatria e a psicossomática, mas também a psicologia social e a antropologia, uma vez que o objeto da psicanálise, o inconsciente, está na vida social. Esses encontros se dão no nível dos conceitos, ou seja, a psicologia, a sociologia e a antropologia utilizam conceitos da psicanálise. Segundo o autor, a diferença está na prática. A psicanálise pode ir além das fronteiras com outras disciplinas (psicoterapia, psiquiatria, psicologia etc.), mas cada uma tem 
sua prática. Para ele, a razão ocidental só consegue um pacto de convivência pacífica com a psicanálise sob a condição de anexá-la às ciências: psicologia, biologia, sociologia (o que acontece com a psicanálise norte-americana, por exemplo), filosofia (como é o caso da psicanálise existencial, Daseinanalyse). Garcia-Roza (1987) já apontava tais questões ao indagar: onde situar a psicanálise?

A resposta pode ser: em nenhum lugar preexistente. A psicanálise estaria, nesse caso, operando uma ruptura com o saber existente e produzindo o seu próprio lugar. Epistemologicamente, ela não se encontra em continuidade com saber algum, apesar de arqueologicamente estar ligada a todo um conjunto de saberes sobre o homem, que se formou a partir do século XIX. (Garcia-Roza, 1987, p. 22)

Fonteles (2015) demonstra a invisibilidade da psicanálise nas agências brasileiras de fomento à pesquisa, que não atribuem rubrica específica para pesquisas em psicanálise, a despeito da presença consolidada ao longo dos anos e da produção de teses específicas em psicanálise, nas mais diversas áreas acadêmicas, em diferentes programas de pós-graduação. Se concordamos que as agências não são compostas por agentes neutros, mas formadas por pesquisadores de cada campo, parece que os próprios agentes do campo, docentes-pesquisadores em psicanálise, pouco fizeram até o momento para reverter tal condição de invisibilidade.

Segundo Aires (2013), a psicanálise permite um "fora-dentro", uma "exclusão interna", um lugar "(des) conhecido" (p.36) que pode ser dita também como "horslieu" (Barthes, 1987, p.47). Sua identidade não estaria pré-definida, constitui-se com cada interlocutor, mas carrega a marca da sua formação: análise, prática clínica e estudos teóricos. Como Freud (1919/2010) postulou em O inquietante, o Unheimlich desperta angústia e horror, "aquela espécie de coisa assustadora que remonta ao que é há muito conhecido, ao bastante familiar" (p.331) ou ainda o que deveria permanecer oculto, mas apareceu. O conceito de êxtimo de Lacan (1960/2008) remete ao Unheimlich freudiano, o mais íntimo, o mais interior e, ao mesmo tempo, o que está excluído. A psicanálise pode ser considerada um Unheimlich da universidade. Desde o início, as ideias freudianas estão presentes na universidade que, por sua vez, exerceu e exerce importante papel em sua produção e divulgação. Se a psicanálise é recalcada pelo discurso da ciência, o recalcado retorna ao modo de sintoma. Apesar de ter surgido do terreno da ciência moderna, não deixou de marcar a exclusão daquilo que, desde o inicio, já anunciava sua ruptura e subversão.

A experiência analítica faz com que o sujeito interrogue o saber. Se o analista não se coloca como tal, também na universidade, não há transmissão, nem produção de saber. A psicanálise seria o sujeito recalcitrante da universidade, ou seja, aquele que, interrogando o saber, faz com que o pesquisador se questione, o que o leva também a correr riscos (Stengers citado por Latour, 1997).

A psicanálise na universidade interroga a ciência e os modos de fazer pesquisa, mas também deve interrogar-se a si própria. Somente assim, terá efeito fecundador, para utilizar um termo de Freud (1919/2010b) ao se referir à psicanálise na universidade, alargando seus parâmetros e beneficiandose de outros saberes, tal como fizeram Freud e Lacan.

Não buscamos aqui polemizar sobre as condições de cientificidade da psicanálise. Cabe, entretanto lembrar as palavras de Freud: "O futuro provavelmente atribuirá muito maior importância à psicanálise como ciência do inconsciente do que como um procedimento terapêutico" (Freud, 1926/1996, pp.254-255). Se a interdisciplinaridade foi condição necessária para a construção do campo psicanalítico, a transdisciplinaridade forneceu elementos que justificam sua presença na universidade. Ao estabelecer pontes com diferentes campos, fazendo aquele edifício teórico ser atravessado por marcas outras e modificarse, Freud viveu, operou e transmitiu uma verdadeira experiência, instituindo uma nova episteme. Defendemos aqui a tese de que o estatuto da psicanálise corresponde mais à práxis transdisciplinar do que ao simples diálogo ou integração interdisciplinar. Desse modo, mais do que uma psicanálise aplicada habitando um imaginário "entre-lugar", a psicanálise pode ser tomada como o Unheimlich em relação à universidade, fornecendo-lhe "extimidade" (Lacan, 1991) ou exterioridade íntima, a exclusão interna que retorna sob a forma de subversão.

\section{REFERÊNCIAS}

Aires, S. (2013). Imagens do analista na universidade. Trivium, 5(1), 30-38.

Almeida-Filho, N. (2005). Transdisciplinaridade e o Paradigma Pós-Disciplinar na Saúde. Saúde e Sociedade, 14(3), 30-50.

Almeida-Filho, N., \& Coutinho, D. (2013). Inter-transdisciplinaridade na educação superior no Brasil. In: T, Gambi, D. Consentino, \& B. Gaydesczka (Org.), O Desafio da Interdisciplinaridade: Reflexões sobre a experiência do Bacharelado Interdisciplinar da Unifal-MG (pp. 21-32). Belo Horizonte: Fino Traço.
Althusser, L. (1993). Trois notes sur la théorie des discours. In Écrits sur la psychanalyse (pp. 111-170). Paris: Stock/IMEC. (Trabalho original publicado em 1966)

Althusser, L. (1996). Psychanalyse et sciences humaines: Deux conferences. Paris: Le Livre de Poche. (Trabalho original publicado em 1964)

Althusser, L. (2000). Freud e Lacan. In L. Althusser, Freud e Lacan. Marx e Freud (4a ed., W. J. Evangelista, Trad.). Rio de Janeiro: Graal. (Trabalho original publicado em 1964) 
Assoun, P-L. (1978). Freud: A filosofia e os filósofos (H. Japiassu, Trad.). Rio de Janeiro: Francisco Alves.

Assoun, P-L. (1997). Psychanalyse. Paris: PUF.

Barthes, R. (1987). O prazer do texto (J. J. Guinsburg, Trad.) São Paulo: Perspectiva. (Trabalho original publicado em 1973)

Barthes, R. (1997). Aula inaugural da cadeira de Semiologia Literária do Colégio de França, pronunciada dia 7 de janeiro de 1977 (Leyla Perrone-Moisés, Trad.). São Paulo: Cultrix.

Coutinho, D. (2004). Tempo perdido e reinventado: Memória e contingência em literatura e psicanálise. (Tese de Doutorado). Universidade Federal da Bahia, Salvador, BA, Brasil.

Darbellay, F. (2011). Vers une théorie de l'interdisciplinarité? Entre unité et diversité. Nouvelles Perspectives en Sciences Sociales, 7(1), 65-87.

Fonteles, C. (2015). Psicanálise e universidade: Uma análise da produção acadêmica no Brasil (Tese de Doutorado). Universidade Federal da Bahia/Université Paris 7, Salvador/ Paris, Brasil/França.

Freud, S. (1996). Projeto para uma psicologia científica. In Edição Standard Brasileira das Obras Psicológicas Completas de Sigmund Freud (J. Salomão, Trad., Vol. 1, pp. 335-400). Rio de Janeiro: Imago. (Trabalho original publicado em 1950 [1895])

Freud, S. (1996). Delírios e sonhos na Gradiva de Jensen. In Edição Standard Brasileira das Obras Psicológicas Completas de Sigmund Freud (J. Salomão, Trad., Vol.9, pp. 15-88). Rio de Janeiro: Imago. (Trabalho original publicado em 1907)

Freud, S. (1996). Romances familiares. In Edição Standard Brasileira das Obras Psicológicas Completas de Sigmund Freud (J. Salomão, Trad., Vol.9, pp. 217-224). Rio de Janeiro: Imago. (Trabalho original publicado em 1909)

Freud, S. (1996). A questão da análise leiga: conversações com uma pessoa imparcial. In Edição Standard Brasileira das Obras Psicológicas Completas de Sigmund Freud (J. Salomão, Trad., Vol.20, pp. 175-250). Rio de Janeiro: Imago. (Trabalho original publicado em 1926)

Freud, S. (2010). Deve-se ensinar a psicanálise nas universidades? In Obras Completas (Paulo César de Souza, Trad., Vol. 14, pp. 377-381). São Paulo: Companhia das Letras. (Trabalho original publicado em 1919)

Freud, S. (2011). Psicanálise e Teoria da Libido. In Obras Completas (P. C. de Souza, Trad., Vol. 15, pp. 273-308). São Paulo: Companhia das Letras. (Trabalho original publicado em 1923)

Freud, S. (2011). As resistências da psicanálise. In Obras Completas (P. C. de Souza, Trad., Vol. 16, pp. 252-266). São Paulo: Companhia das Letras. (Trabalho original publicado em 925)

Freud, S. (2012). O interesse da Psicanálise. In Obras Completas (P. C. de Souza, Trad., Vol. 11, pp. 328-363). São Paulo: Companhia das Letras. (Trabalho original publicado em 1913)
Freud, S. (2012a). Contribuição à História do Movimento Psicanalítico. In Obras Completas (P. C. de Souza, Trad., Vol. 11, pp. 245-327). São Paulo: Companhia das Letras. (Trabalho original publicado em 1914)

Freud, S. (2014). Conferências introdutórias à psicanálise. In Obras Completas (P. C. de Souza, Trad., Vol. 13, pp. 14-613). São Paulo: Companhia das Letras. (Trabalho original publicado em 1917)

Garcia-Roza, L.A. (1987). Freud e o inconsciente (3a ed.). Rio de Janeiro: Jorge Zahar.

Lacan, J. (1991). O seminário, livro 7: A ética da psicanálise. (A. Quinet, Trad.). Rio de Janeiro: Jorge Zahar, 1991. (Trabalho original publicado em 1959-60)

Latour, B. (1997). Des sujets récalcitrants. La Recherche, 301, 88.

Milner, J-C. (1996). A obra clara. Lacan, a ciência, a filosofia. Rio de Janeiro: Jorge Zahar.

Müller-Braunschweig, C. (1985). Exposé historique sur l'enseignement, son organization et sa gestion. In On forme des psychanalystes. Rapport original sur les dix ans de l'Institut Psychanalytique de Berlin 1920-1930 (pp. 73-114). Paris: Denoël.

Nicolescu, B. (2002). O manifesto da transdisciplinaridade. Recuperado de http://www.ruipaz.pro.br/textos/manifesto.pdf

Nicolescu, B. (2009). Contradição, lógica do terceiro incluído e níveis de realidade. Recuperado de http://cetrans.com.br/ textos/contradicao-logica-do-terceiro-incluido-e-niveis-derealidade.pdf

Nicolescu, B. (2013). La necesidad de la transdisciplinariedad en la educación superior. Trans-Pasando Fronteras: Revista Estudiantil de Assuntos Transdisciplinares. Retirado de https:// www.icesi.edu.co/revistas/index.php/trans-pasando_fronteras/ article/view/1624

Pombo, O. (2008). Epistemologia da interdisciplinaridade. Ideação, $10(1), 9-40$.

Piaget, J. (1972). L'epistémologie des relations interdisciplinaires. Recuperado de http://www.fondationjeanpiaget.ch/fjp/site/ textes/VE/jp72_epist_relat_interdis.pdf

Rank, O., \& Sachs, $\overline{\mathrm{H}} .(19 \overline{8} 0)$. Psychanalyse et sciences humaines. Paris: Presses Universitaires de France. (Obra original publicada em 1913)

Schmid, A-F, Mambrini-Doudet, M., \& Hatchuel, A. (2011). Une nouvelle logique de l'interdisciplinarité. Nouvelles Perspectives en Sciences Sociales, 7(1), 183-197.

Viotti, E. B., Oliveira Jr., C. D., Viotti, R. B., Pinho, R. D., Daher, S., \& Vermulm, R. (2010). Doutorados e doutores titulados no Brasil: 1996-2008. In Centro de Gestão e Estudos Estratégicos (Org.), Doutores 2010: Estudos da demografia da base técnicocientifica (pp. 61-194). Brasília: Centro de Gestão e Estudos Estratégicos. 